\section{Closure of surgical wounds: a rapid eversion technique}

\author{
Nicholas Hemmings, Greg J. Knepil \\ Department of Oral \& Maxillofacial \\ Surgery, Gloucestershire Hospitals NHS \\ Foundation Trust, Gloucestershire Royal \\ Hospital, Gloucester, UK
}

\begin{abstract}
There are many suturing techniques available for the closure of skin incisions. The authors present a continuous suturing technique which is simple and quick to perform, eliminates the need for an assistant to follow, is easy to remove, and produces an everted wound margin with evenly distributed tension. The authors believe this technique produces a cosmetically superior scar, which is beneficial to the patient and to the surgeon.
\end{abstract}

\section{Technical note}

This suturing technique can be used for small or large wounds, which are straight or curved, and is best suited for thicker skin types without undue tension. Deep sutures are still recommended when closing the subcutaneous structures within a deep wound. This technique combines interrupted and horizontal running mattress sutures, in a continuous alternating fashion. The interrupted sutures prevent the mattress sutures submerging, controls precise appo-
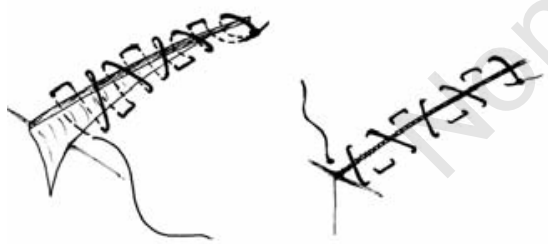

Figure 1. Diagrammatic representation of during and after wound closure. sition of everted wound edges, and allows for easy removal of the suture in due course. Suture removal is facilitated as the interrupted component provides easy access for a scissor blade or scalpel to be inserted between the suture and skin surface. The suture can then be cut at the skin surface on one side leaving a long tail. If this is done to each interrupted component along the length of the wound, the long tails can easily be grasped and teased out which allows removal of the suture material under minimum tension, and avoids dragging the non-buried parts of the suture through the wound. The horizontal mattress sutures evert the wound edges, provide haemostasis, and maintain tension evenly across the wound. ${ }^{1,2}$ The suture technique is initiated and closed with a standard surgeons knot, just as one would tie if performing a conventional continuous suture. The continuous component of the suture technique prevents suture marks from forming. ${ }^{2}$ We believe that this technique incorporates many of the established practical and cosmetic advantages of interrupted and mattress sutures, and avoids many of the disadvantages, particularly with regard to wound care and suture removal.

Figure 1 demonstrates the suturing technique diagrammatically during and after closure. The left hand picture in Figure 2 demonstrates the closure of two wounds on the same patient, performed by two consultant surgeons, using suturing techniques of their own preference. The continuous mattress technique discussed here is shown on the patient's right side and middle, and simple interrupted sutures on the patients left side. The right hand picture demonstrates the cosmetic appearance of the resulting scar 3 months later.

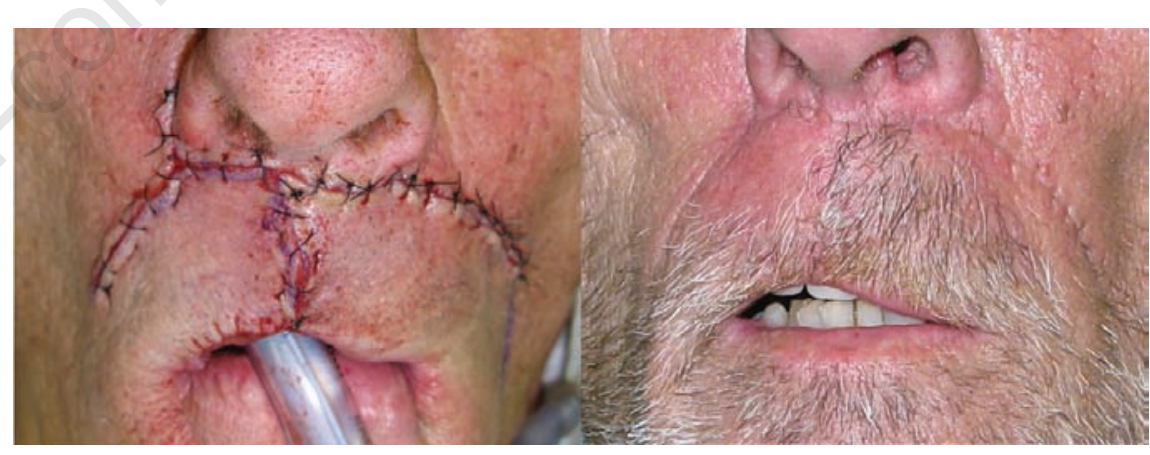

Figure 2. Wound appearance immediately post-op and 3 months later.
Correspondence: Nicholas Hemmings, Department of Oral \& Maxillofacial Surgery, Gloucestershire Hospitals NHS Foundation Trust, Gloucestershire Royal Hospital, Great Western Road, Gloucester, Gloucestershire, GL1 3NN, UK. Tel. +44.0.8454.222222

E-mail: nicholas.hemmings@nhs.net

Key words: wound closure; suture technique; cosmetic.

Received for publication: 12 July 2011.

Accepted for publication: 19 September 2011.

This work is licensed under a Creative Commons Attribution NonCommercial 3.0 License (CC BYNC 3.0).

CCCopyright N. Hemmings and G.J. Knepil, 2011 Licensee PAGEPress, Italy

Surgical Techniques Development 2011; 1:e22 doi:10.4081/std.2011.e22

\section{References}

1. Moy RL, Waldman B, Hein D. A review of sutures and suturing techniques. J Dermatol Surg Oncol 1992;18:785-95.

2. Moody BR, McCarthy JE, Linder J, Hruza GJ. Enhanced cosmetic outcome with running horizontal mattress sutures. Dermatol Surg 2005;31:1313-6. 